\title{
Selected Topics on Enablers for Next-Generation Information Systems Development: Editorial Introduction to Issue 25 of CSIMQ
}

\author{
Robert Andrei Buchmann* \\ Business Informatics Research Center, Babeș Bolyai University, \\ Teodor Mihali Street Nr. 58-60, Cluj Napoca, 400591, Romania \\ robert.buchmann@ubbcluj.ro
}

The 25th issue of CSIMQ presents four articles that investigate novel enablers for information systems development. Information systems development is going through major transformations not only on process level, but also in terms of its technological enablers, often determined by digital transformation initiatives and digital engineering techniques that require historically disconnected skills and a shifting or integration of abstraction layers that can serve both system builders and innovation managers [1]. Process automation, Industry 4.0, low-code software engineering, machine learning are only a few popular examples of such technological enablers.

Three of the papers selected for this issue deal with a particular kind of technological enabler agile conceptual modeling methods in the sense formulated by [2]. Two of those papers describe both design decisions and usable tools showcasing specific situations of model-driven engineering where established languages (BPMN and ER) have been extended for low-code software development with some technological specificity. The third paper has a wider enterprise-oriented focus, describing design decisions and applicability to a decision support problem. A fourth paper investigates Industry 4.0 adoption and readiness in SMEs by applying conceptual analysis on results of a systematic literature review.

The first paper, authored by Andrei Chiș and titled A Modeling Method for Model-Driven API Management, extends BPMN with an additional model type to capture constructs specific to REST APIs and HTTP requests. This allows a diagrammatic abstraction of HTTP-based data retrievals that can serve either in the design phase of a To-Be API ecosystem or in the testing phase of an As-Is ecosystem - both in a process-centric manner, since request configurations are mapped on BPMN elements.

The second paper, authored by Carmen Gog and titled Agile Development of PHP Websites: a Model-Aware Approach, is another example of a technology-specific modeling method - this time aiming to support traditional MVC-based development for PHP websites, with an illustrative example focusing on CakePHP integration. Webpage flows created with the proposed

\footnotetext{
* Corresponding author

(C) 2020 Robert Andrei Buchmann. This is an open access article licensed under the Creative Commons Attribution License (http://creativecommons.org/licenses/by/4.0).
}

Reference: R. A. Buchmann, "Selected Topics on Enablers for Next-Generation Information Systems Development: Editorial Introduction to Issue 25 of CSIMQ," Complex Systems Informatics and Modeling Quarterly, CSIMQ, no. 25, pp. I-II, 2020. Available: https://doi.org/10.7250/csimq.2020-25.00

Additional information. Author's ORCID iD: R. A. Buchmann - https://orcid.org/0000-0002-7385-1610. PII S225599222000142X. Received: 20 December 2020. Available online: 31 December 2020. 
modeling method are stored as semantic graphs and queried to fill certain PHP code templates at run-time, with RDF employed as the key interoperability mechanism.

The third paper was written by Ibrahim Koura, Frederick Benaben, Juanqiong Gou and Audrey Fertier and is titled The Periodic Table of Industries: Detection of Collaboration Opportunities Based on an Imitation of the Mendeleev Periodic Table of Elements. Although it is not presented explicitly as a modeling tool, its core contribution has sufficiently rich design decisions and applicability indications (on a showcase example) to inform future modeling method engineers on the topic of collaboration network configurations considering KPI effects. The proposal is preceded by an extensive literature review on collaborative networks, from which the addressed design problem was derived.

In the last paper, titled Exploring Readiness of SMEs for Industry 4.0, Natalie Grufman, Sinéad Lyons and Eriks Sneiders report on an extensive systematic literature review on Industry 4.0 adoption and associated challenges for SMEs. A readiness framework inspired by the IMPULS assessment model [3] was employed with some modifications, leading to the conclusion that SMEs are still learners with respect to Industry 4.0 adoption and barriers.

These are the four papers selected based on the valuable feedback from at least three reviewers per each paper. The CSIMQ editorial team would like to thank the reviewers for their substantial advice; we would also like to thank all authors who submitted their research work for this issue.

\section{References}

[1] D. Karagiannis, R. A. Buchmann, X. Boucher, S. Cavalieri, A. Florea, D. Kiritsis, and M. Lee, "OMiLAB: a smart innovation environment for digital engineers," Proceedings of PRO-VE 2020, IFIP AICT, Springer, vol. 598, pp. 273-282, 2020. Available: https://doi.org/10.1007/978-3-030-62412-5_23

[2] D. Karagiannis, "Conceptual modelling methods: the AMME engineering approach," Proceedings of IE 2016, LNBIP, Springer vol. 273, pp. 3-19, 2017. Available: https://doi.org/10.1007/978-3-319-73459-0_1

[3] K. Lichtblau, V. Stich, R. Bertenrath, M. Blum, M. Bleider, A. Millack, K. Schmitt, E. Schmitz, and M. Schröter, "IMPULS-industrie 4.0-readiness," Impuls-Stiftung des VDMA, Aachen-Köln, 2015. Available: https://industrie40.vdma.org/documents/4214230/26342484/Industrie_40_Readiness_Study_1529498007918.pdf /0b5fd521-9ee2-2de0-f377-93bdd01ed1c8 Accessed on March 15, 2020. 